\title{
EFEITO DO Ti, Nb E V NO CRESCIMENTO DE GRÃO AUSTENÍTICO DE UM AÇO FERRAMENTA PARA TRABALHO A QUENTE
}

\author{
Rafael Agnelli Mesquita (1) \\ Celso Antonio Barbosa (2)
}

\section{Resumo}

A adição de elementos microligantes para refino de grão de aços baixa liga vem sendo empregada em muitas aplicações tecnológicas. O presente trabalho avalia o efeito dos elementos $\mathrm{V}, \mathrm{Nb}$ e Ti no tamanho grão austenítico do aço VMO (DIN WNr. I.27।4), um aço ferramenta normalmente utilizado para matrizes de forjamento. Foram produzidas várias corridas experimentais, variando os teores de $\mathrm{V}, \mathrm{Nb}$ e $\mathrm{Ti}$ e, conseqüentemente, modificando as condições de precipitação de nitretos e carbonitretos. A composição padrão do material já apresenta pequenos teores de $\mathrm{V}$. $\mathrm{O}$ efeito do $\mathrm{Nb}$ foi avaliado substituindo o $\mathrm{V}$ e, também, somado à composição padrão. Para o Ti, foram produzidas composições variando o teor de $\mathrm{Ti}$ e a razão $\mathrm{Ti} / \mathrm{N}$. As composiçöes foram estudadas após austenitização entre 850 e $1260^{\circ} \mathrm{C}$; as temperaturas mais elevadas visam avaliar o tamanho de grão durante 0 aquecimento prévio ao forjamento do material. As curvas de tamanho de grão obtidas, em função da temperatura de austenitização, permitem identificar o efeito de cada elemento na barreira ao crescimento e identificar a melhor relação Ti/N.

Palavras-chave: aço ferramenta para trabalho a quente, refino de grão, microadições.

\section{Effect of Ti, Nb AND V on the Austenite Grain Growth of a Hot Work Tool Steel}

\begin{abstract}
Microalloying additions for grain refining of low alloy steels have been employed in many technological applications. The present work evaluates the effect of $\mathrm{V}, \mathrm{Nb}$ and $\mathrm{Ti}$ on austenite grain size of steel $\mathrm{VMO}$ (DIN WNr I.27| 4), tool steel usually employed in forging dies. Several experimental heats were produced with different $\mathrm{V}, \mathrm{Nb}$ and $\mathrm{Ti}$ contents and, as a consequence, with distinct carbonitride precipitation conditions. The basic composition of this tool steel contains a specified $V$ content. The effect of $\mathrm{Nb}$ was thus evaluated substituted for $\mathrm{V}$ and also on the basic composition (with $\mathrm{V}$ ). For Ti additions, heats variying Ti content and $\mathrm{Ti} / \mathrm{N}$ ratio. The compositions were studied after austenitizing between 850 to $1260^{\circ} \mathrm{C}$; higher temperatures aim to simulate grain growth occurred during soaking, previous to steel forging. Grain size curves versus austenitizing temperature lead to analysis of each element effect on grain pinning, and to determine the best $\mathrm{Ti} / \mathrm{N}$ ratio.
\end{abstract}

Key-words: hot tool steel, grain refining, microadditions.

\section{INTRODUÇÃO}

O uso de distribuições de partículas finas constitui o principal mecanismo para se promover microestruturas com grãos refinados e, conseqüentemente, melhores propriedades mecânicas. $(1,2)$ Neste sentido, destacam-se os aços microligados, que historicamente vem sendo estudados, desenvolvidos e aplicados tecnologicamente.(3) $\mathrm{O}$ efeito das partículas finas é tanto maior quanto maior a fração em volume e, para a mesma fração, quanto mais refinadas as partículas.(4-5)
Em aços, são tradicionalmente empregadas pequenas adiçốes de $\mathrm{Al}, \mathrm{V}$, Ti e $\mathrm{Nb}$, normalmente com o objetivo de controle do grão em alta temperatura ou refino durante a recristalização. $O$ presente estudo é focado no primeiro aspecto. $\mathrm{O}$ crescimento de grão austenítico durante aquecimento prévio a conformação, encharque, pode ser retardado devido à presença de precipitados não dissolvidos (nitretos, carbonetos ou carbonitretos). Assim, grãos austeníticos

(1) Engenheiro de Materiais, Membro da ABM, Mestre em Ciência e Engenharia de Materiais, Pesquisador da Villares Metals S. A., Sumaré, SP, Brasil, e-mail: rafael.mesquita@villaresmetals.com.br.

(2) Engenheiro Metalurgista, Membro da ABM, Gerente de Tecnologia da Villares Metals S. A., Sumaré, SP, Brasil, e-mail: celsoa@villares.com.br. 
refinados podem ser conservados nas altas temperaturas prévias ao forjamento.(6)

O presente trabalho busca avaliar 0 efeito de microadiçōes de $\mathrm{V}, \mathrm{Nb}$ e $\mathrm{Ti}$ no crescimento de grão do aço VMO (DIN WNr. 1.2714), um aço baixa liga e de médio teor de carbono. Este material é utilizado em ferramentas para trabalho a quente, principalmente em matrizes de grandes dimensôes para forjamento em prensas ou martelos. As temperaturas de forjamento utilizadas em sua manufatura são da ordem de $1250^{\circ} \mathrm{C}$ e, devido às elevadas dimensōes dos blocos forjados, são empregados longos tempos de encharque. $O$ controle do crescimento de grão no aço VMO é importante na etapa de conformação, bem como na austenitização para a têmpera final do material. Ambos aspectos foram avaliados, sendo, para tanto, estudadas temperaturas de austenitização entre 850 e $1260^{\circ} \mathrm{C}$.

\section{MATERIAIS E MÉTODOS}

Para o presente estudo, foram avaliadas corridas experimentais produzidas em forno de indução a vácuo, variando os teores de $\mathrm{Ti}, \mathrm{V}, \mathrm{Nb}$ e N; a composição base do aço VMO (DIN I.2714) foi mantida para todos. Os lingotes, de aproximadamente $50 \mathrm{~kg}$ e $140 \mathrm{~mm}$ de seção média, foram forjados até bitolas de seção $60 \mathrm{x}$ $80 \mathrm{~mm}^{2}$, totalizando média de 4 vezes em redução em área. Previamente ao forjamento, passaram por um encharque de 6 horas em temperaturas de $1230^{\circ} \mathrm{C}$ para as ligas contendo $\mathrm{Nb}$ e $\mathrm{V}$ e $1260^{\circ} \mathrm{C}$ para as composiçóes com Ti. A temperatura final de forjamento foi da ordem de $850^{\circ} \mathrm{C}$ e o recozimento posterior foi subcrítico, a $690^{\circ} \mathrm{C}$ por 15 horas.

Foram estudadas composiçôes contendo as seguintes combinaçôes de elementos microligantes (ver Tab. I): $\mathrm{V}, \mathrm{Nb}, \mathrm{V}+\mathrm{Nb}, \mathrm{V}+\mathrm{Ti}$. Para as ligas com microadiçóes de $\mathrm{Ti}$, os teores de $\mathrm{N}$ foram controlados e avaliada a relação $\mathrm{Ti} / \mathrm{N}$.

Os teores de $\mathrm{Nb}$ foram definidos com auxílio da equação de Nordberg e Aronsson,(7) do produto de solubilidade do $\mathrm{NbC}$ na austenita, de aços de baixo carbono (equação I), ou seja:

$\log \left[(\% C)^{0,87} \cdot(\% N b)\right]=3,11-\frac{7520}{T} . \quad($ equação I)
Esta relação foi avaliada em aços de médio e alto carbono, (6) mostrando boa correlação e, por isso, foi aplicada no presente trabalho.

O cálculo do teor de $\mathrm{Nb}$ em equilíbrio durante o encharque $\left(1230^{\circ} \mathrm{C}\right)$ foi, assim, baseado no equilíbrio $\mathrm{Nb}, \mathrm{C}$ e $\mathrm{NbC}$ na austenita, descrito pela equação I. Utilizando o teor de $\mathrm{C}$ da composição química do aço em questão $(\mathrm{C}=0,56 \%)$, o teor de $\mathrm{Nb}$ em solução sólida é calculado como $0,021 \%$.

Tabela I. Composição química dos aços estudados, em porcentagem em massa e balanço em $\mathrm{Fe}$.

\begin{tabular}{|c|c|c|c|c|c|c|c|c|c|c|c|c|c|c|}
\hline Comp. & C & $\mathbf{S i}$ & $M n$ & $\mathrm{Cr}$ & $\mathbf{N i}$ & Mo & $\mathbf{P}$ & S & Al & v & Nb & $\underset{(\mathrm{ppm})}{\mathrm{Ti}}$ & $\underset{(\mathrm{ppm})}{\mathbf{N}}$ & $\mathbf{T i} / \mathbf{N}$ \\
\hline 1 & 0.55 & 0.27 & 0.72 & 1.10 & 1.63 & 0.52 & 0.013 & 0,002 & 0.041 & 0.07 & $<0,01$ & $<50$ & 16 & - \\
\hline 2 & 0.55 & 0.26 & 0,70 & 1.10 & 1.65 & 0.51 & 0.013 & 0,005 & 0.026 & 0.07 & $<0,01$ & $<50$ & 10 & - \\
\hline 3 & 0.55 & 0.26 & 0.67 & 1.09 & 1.62 & 0.52 & 0.013 & 0,003 & 0.023 & $<0.01$ & 0.02 & $<50$ & 98 & - \\
\hline 4 & 0.55 & 0.26 & 0.70 & 1.10 & 1.63 & 0.52 & 0.013 & 0,004 & 0.029 & $<0,01$ & 0.03 & $<50$ & 10 & - \\
\hline 5 & 0.55 & 0.27 & 0.70 & 1.10 & 1.65 & 0.51 & 0.012 & 0.003 & 0,033 & $<0,01$ & 0.05 & $<50$ & 16 & - \\
\hline 6 & 0,56 & 0,26 & 0,68 & 1,10 & 1,65 & 0,52 & 0,013 & 0,002 & 0,042 & 0,07 & 0,04 & $<50$ & 24 & - \\
\hline 7 & 0.55 & 0.26 & 0,69 & 1.07 & 1.61 & 0.50 & 0.014 & 0,003 & 0.017 & 0.07 & $<0.01$ & $40^{*}$ & 39 & 1.0 \\
\hline 8 & 0.56 & 0.27 & 0.69 & 1.07 & 1.58 & 0.51 & 0.010 & 0,004 & 0,034 & 0.07 & $<0,01$ & 80 & 34 & 2.4 \\
\hline 9 & 0,56 & 0,27 & 0,69 & 1,09 & 1,55 & 0,51 & 0,011 & 0,004 & 0,027 & 0,07 & $<0,01$ & 80 & 52 & 1,5 \\
\hline 10 & 0,56 & 0,27 & 0,69 & 1,10 & 1,58 & 0,50 & 0,011 & 0,002 & 0,026 & 0,07 & $<0,01$ & 170 & 45 & 3,8 \\
\hline
\end{tabular}

Em trabalho anterior, $(8)$ foi verificado que teores excessivamente elevados de $\mathrm{Nb}$, como $0,13 \%$, promoviam a formação de carbonetos eutéticos grosseiros, ricos em $\mathrm{Nb}$, que podem prejudicar a tenacidade. $\left({ }^{\prime}\right)$ Sendo esta propriedade essencial para as aplicaçóes do aço VMO, o presente trabalho utilizou composiçôes com teores de $\mathrm{Nb}$ próximos ou ligeiramente maiores que os calculados pela Equação I.

O refino de grão via $\mathrm{Ti}$ atua pela formação de carbonitretos ou nitretos, estes últimos mais importantes para altas temperaturas e os mais estudados.(10-20) Existe certa divergência quando à equação de cálculo do produto de solubilidade do TiN na austenita,(10-14) mas a mais utilizada é:(14)

$$
\log [(\% T i) \cdot(\% N)]=-\frac{8000}{T}+0,32 .(\text { equação } 2)
$$

Para composiçōes com cerca de 50 ppm de $\mathrm{N}$ (valor próximo ao obtido em aciaria elétrica após desgaseificação a vácuo), a equação 2 fornece um valor muito baixo de $\mathrm{Ti}$ em solução sólida a $1230^{\circ} \mathrm{C}$ : cerca de $0,002 \%$. Assim, denota-se a alta estabilidade e a baixa solubilidade do $\mathrm{TiN}$ na austenita, ${ }^{(10-15)}$ já indicando a eficiência dessas partículas no controle do crescimento do grão austenítico.(16-18)

Seguindo informaçôes de literatura, $(16-17,19-20)$ os teores de Ti e $\mathrm{N}$ foram fixados em razōes próximas à estequiométrica $(\mathrm{Ti} / \mathrm{N}$ $=3,42$ em \% massa) ou com maior teor de $\mathrm{N}$ (composições hipoestequiométricas).

Temperaturas de austenitização entre 850 e $1260^{\circ} \mathrm{C}$ e tempos fixos de I horaforam empregados. Todas as amostras foram temperadas em óleo, e o tamanho de grão austenítico foi medido pelo método de Hillard,(21) após ataque com "teepol".(8) O desvio-padrão das medidas ficou entre 10 e $15 \%$ da média. 


\section{RESULTADOS E DISCUSSÃO}

A evolução do tamanho de grão austenítico em função da temperatura de austenitização para as composições I e 2, com V, é apresentada na Figura I. Os valores encontrados mostram pequena variação. Assim, comparando as pequenas diferenças de composição química destas ligas, a Figura I indica uma boa precisão do método experimental empregado. As diferenças de tamanho de grão entre as corridas I e 2, são inferiores a $6 \%$ em qualquer ponto [na escala logarítimica, Ln(D)].

Na Figura 2 são apresentados os valores de tamanho de grão austenítico para as composiçōes 3 a 6 , com $\mathrm{Nb}$ e V+Nb. Os dados são representados em gráficos do tipo $\operatorname{Ln}(D) \times I / T$, a fim de identificar se seguem o modelo que, para aços ao carbono, é dado pela seguinte equação:(6)

$$
D=K \cdot \exp \left(-\frac{E a}{2 R T}\right), \text { (equação } 3 \text { ), }
$$

em que $D$ é o tamanho de grão, $K$ uma constante, $R$ a constante universal dos gases, $T$ a temperatura absoluta e $E_{a}$ a energia de ativação, igual à inclinaçâo da curva $\operatorname{Ln}(\mathrm{D}) \times \mathrm{I} / \mathrm{T}$.

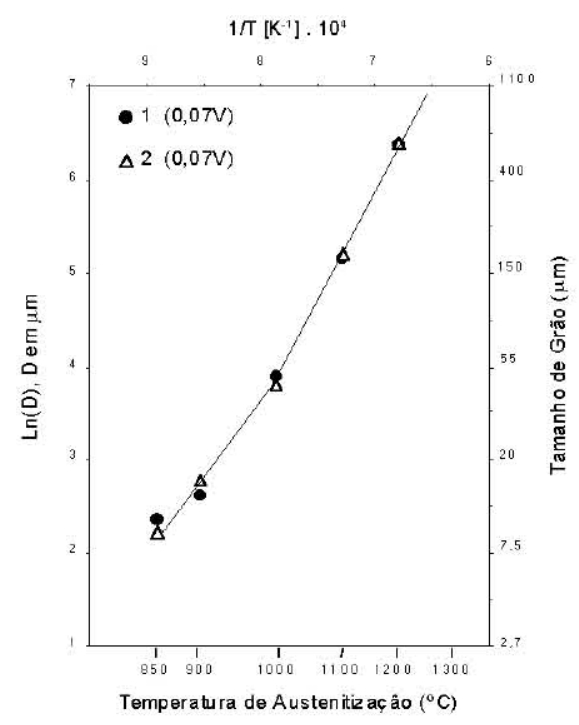

Figura I. Tamanho de grão austenítico das ligas I e 2, em função da temperatura de austenitização. Tempo fixo de I hora para todas as temperaturas. Os teores de $V$ indicados são de porcentagem em massa.

A comparação deste modelo nos dados da Figura 2, e também da Figura I, mostra não haver correlação linear para toda faixa de temperatura. São identificadas duas energias de ativação, dadas pelas duas inclinaçôes das curvas, para temperaturas acima e abaixo de $1050^{\circ} \mathrm{C}$, aproximadamente. Isto é mais evidente para a liga 3 , com teor de $0,02 \% \mathrm{Nb}$.

Este efeito de crescimento de grão em dois estágios já havia sido identificado por Coladas et al.,(6) estudando aços médio teor de $\mathrm{C}$ microligados ao $\mathrm{Nb}$. Mostra que durante o estágio de crescimento lento o número partículas finas de carbonitretos é suficiente para barrar o crescimento de grão. Quando a temperatura atinge um valor superior a uma temperatura crítica, $T_{c}$, o número de partículas torna-se insuficiente, devido ao seu coalescimento ou dissolução. Conseqüentemente, inicia-se o estágio de rápido crescimento, em que apenas as partículas não dissolvidas durante 0 encharque, e mais grosseiras, podem atuar no controle do crescimento.

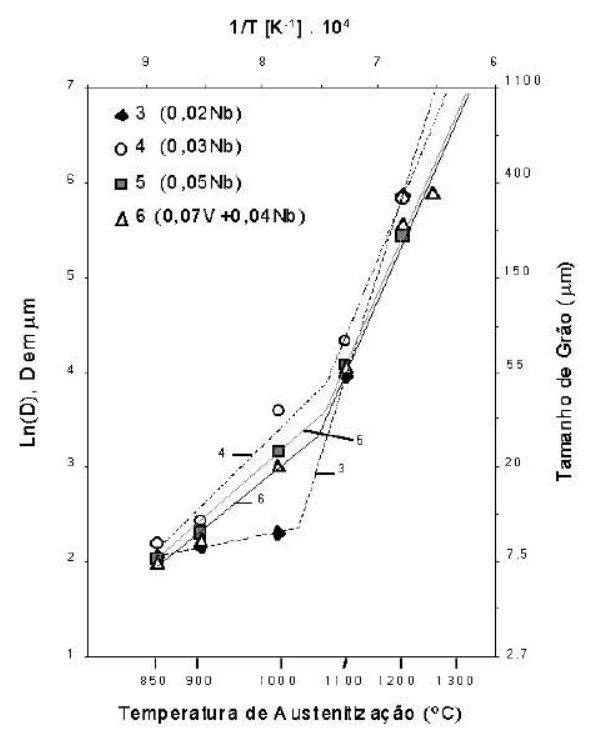

Figura 2. Tamanho de grão austenítico das ligas 3 a 6, em função da temperatura de austenitização. Tempo fixo de I hora para todas as temperaturas. Os teores de $\mathrm{V}$ e $\mathrm{Nb}$ indicados estäo em porcentagem em massa.

Os resultados das Figuras I e 2 podem ser assim entendidos: os carbonitretos finos de $V$ ou $\mathrm{Nb}$ atuam como barreiras nas temperaturas mais baixas. Mas, nas temperaturas mais altas, coalescem ou dissolvem, dando origem a um crescimento de grão mais acelerado. A mudança de comportamento ocorre em torno de $1000^{\circ} \mathrm{C}$ para as ligas com $V$ e $1050^{\circ} \mathrm{C}$ para as ligas com $\mathrm{Nb}$. Esta diferença pode ser explicada pela maior resistência ao coalescimento e à dissolução do carbonitreto de $\mathrm{Nb}$ em relação ao carbonitreto de $\mathrm{V},(15)$ aumentando a temperatura crítica.

Todas as composições com $\mathrm{Nb}$, com exceção da liga 3 , apresentam comportamento próximo em temperaturas menores que $1050^{\circ} \mathrm{C}$. Contudo, em temperaturas mais altas, as ligas com menor teor de $\mathrm{Nb}$ apresentam crescimento mais acelerado. Lembrando que a solubilidade do $\mathrm{Nb}$ pode ser calculada pela equação I, quanto maior o teor de $\mathrm{Nb}$ maior a fração de carbonetos não dissolvidos que, mesmo mais grosseiros, atuam refinando o grão em alta temperatura(6) Isso explica o crescimento menos acelerado acima de $1050^{\circ} \mathrm{C}$ das ligas com $0,04 \%$ e $0,05 \%$ de Nb. 
Tabela 2. Resposta ao tratamento térmico das composiçöes I a 6. Dureza após têmpera em óleo a partir de $850^{\circ} \mathrm{C}$ e revenimento duplo de 2 horas na temperatura indicada.

\begin{tabular}{|c|c|c|c|}
\hline \multicolumn{4}{|c|}{ Dureza em HRC após revenimento a } \\
\hline Composições & $570^{\circ} \mathrm{C}$ & $615^{\circ} \mathrm{C}$ & Observaçăo \\
\hline I & 43,3 & 38,0 & \multirow{4}{*}{$V=0,07 \%$} \\
\hline 2 & 42,4 & 37,7 & \\
\hline 6 & 42,4 & 37,4 & \\
\hline média: & 42.7 & 37.7 & \\
\hline 3 & 39,5 & 34,0 & \multirow{4}{*}{$V<0,01 \%$} \\
\hline 4 & 38,3 & 33,6 & \\
\hline 5 & 38,9 & 34,0 & \\
\hline média: & 38,9 & 33,9 & \\
\hline
\end{tabular}

Além do efeito no refino de grão austenítico, os carbonetos finos de $\mathrm{V}$ e $\mathrm{Nb}$ podem atuar no endurecimento secundário durante o revenimento. Este efeito pode ser analisado na Tabela 2, que apresenta a dureza das ligas com $\mathrm{Nb}$ e $\mathrm{V}+\mathrm{Nb}$, após têmpera e revenimento. Assim como já identificado em trabalhos anteriores, ${ }^{(8)}$ a Tabela 2 mostra que o $\vee$ tem forte efeito sobre $o$ endurecimento secundário. Aumenta a dureza em aproximadamente $3 \mathrm{HRC}$ e promove melhor resistência ao revenimento, pois valores mais altos de dureza são obtidos para uma mesma temperatura de revenimento. Assim, dada a aplicação do aço VMO em matrizes de forjamento a quente, não é interessante a substituição do $V$ por $\mathrm{Nb}$. Nesse sentido, a composição 6 mostra-se a mais interessante das ligas com $\mathrm{Nb}$ estudadas, preservando o teor de $0,07 \%$ de $\mathrm{V}$.

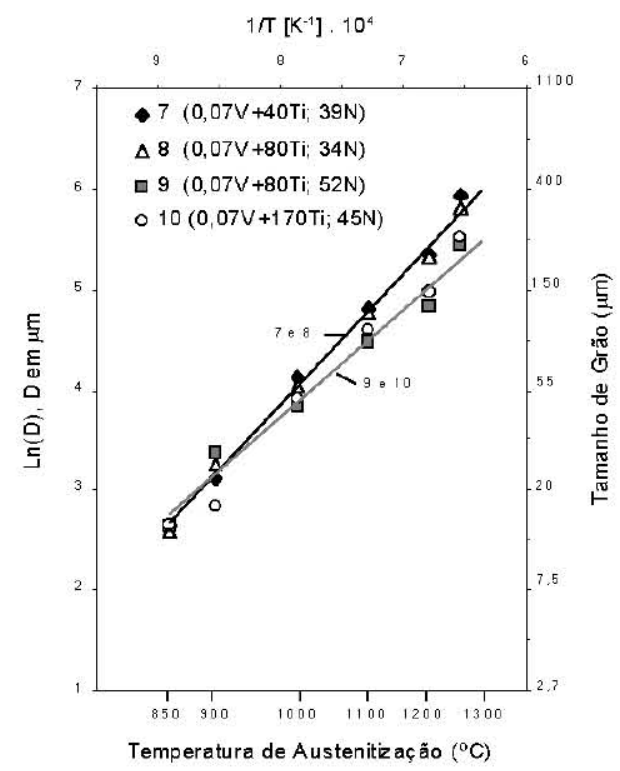

Figura 3. Tamanho de grão austenítico das ligas 7 a 10 , em função da temperatura de austenitização. Tempo fixo de I hora para todas temperaturas. Os teores de $\mathrm{V}$ indicados estäo em porcentagem em massa e os teores de $\mathrm{Ti}$ e $\mathrm{N}$ estäo em $\mathrm{ppm}$. As linhas representam a regressäo linear; as composiçöes 7 e 8 e as 9 e 10 apresentam praticamente a mesma regressão.
A Figura 3 apresenta as curvas de crescimento do grão austenítico das ligas 7 a 10, que apresentam adição de Ti, mas sem remoção do $\mathrm{V}$. O crescimento de grão apresenta a relação linear com toda faixa de temperatura analisada. Isto resulta da maior estabilidade dos carbonitretos finos de $\mathrm{Ti}$.(10-15) Os resultados mostram, também, que composiçôes com $\mathrm{N}$ mais altos geram os tamanhos de grãos mais finos. Teores de Ti muito elevados, como da liga 10 , não parecem ter efeito no refino em alta temperatura. Assim, tais resultados indicam que o refino em alta temperatura, acima de $1100^{\circ} \mathrm{C}$, depende de composições de $\mathrm{N}$ próximo a 50 ppm e teores de Ti entre 80 ppm e 170 ppm, confirmando que relaçốes hipoestequiométricas são interessantes. Isso ocorre porque o excesso de $\mathrm{N}$, especificamente com razão $\mathrm{Tl} / \mathrm{N}$ próxima a 2,0, reduz o teor de Ti em solução sólida (eq. 2), dificultando o coalescimento das partículas e resultando em maior refino em alta temperatura. $(16,19)$

A comparação de três ligas com $\mathrm{V}, \mathrm{V}+\mathrm{Nb}$ e $\mathrm{V}+\mathrm{Ti}$ é apresentada na Figura 4. A energia de ativação (inclinações das curvas) da liga com Ti é constante e inferior às das ligas com $\mathrm{V} e$ $\mathrm{V}+\mathrm{Nb}$; porém os tamanhos de grão da liga com Ti são maiores em temperaturas abaixo de $1100^{\circ} \mathrm{C}$. Isto indica que os carbonitretos de Ti possuem maior resistência ao coalescimento e dissolução, fato já identificado na literatura,(15) porém formam distribuições menos efetivas para refino de grão, devido ao tamanho ou a fração volumétrica das partículas formadas, nas composiçốes do presente estudo.

A firn de estudar, especificamente, o crescimento de grão austenítico em alta temperatura e sua relação com o tamanho de grão prévio a têmpera final do material, amostras das ligas I, 6 e 9 foram submetidas aos seguintes tratamentos: aquecimento a $1260^{\circ} \mathrm{C}$ por I hora, resfriamento até $130^{\circ} \mathrm{C}$ e posterior recozimento subcrítico a $690^{\circ} \mathrm{C}$ por 15 horas. O objetivo foi simular o ciclo de forjamento do lingote, porém sem aplicação da deformação. Em seguida, as amostras foram temperadas a partir de $950^{\circ} \mathrm{C}$, temperatura usual de austenitização do material, e o tamanho de grão austenítico foi avaliado. Os resultados são mostrados na Tabela 3.

O tamanho de grão obtido após este tratamento, para a liga contendo apenas $\mathrm{V}$, foi muito superior ao obtido originalmente (sem o tratamento em alta temperatura). No caso da liga com $\mathrm{Nb}$ e, principalmente, da liga com Ti este fenômeno não ocorre nas mesmas proporções.

Tabela 3. Tamanho de gräo austenítico antes e após o tratamento em alta temperatura. Para a primeira condiçäo, as amostras foram temperadas de forma usual a partir de $950^{\circ} \mathrm{C}$. Para a segunda condiçäo as amostras foram submetidas a um tratamento a $1260^{\circ} \mathrm{C}$, recozidas a $690^{\circ} \mathrm{C}$ e posteriormente temperadas a partir de $950^{\circ} \mathrm{C}$.

\begin{tabular}{ccc}
\hline & Tamanho de Gräo \\
\hline Composicões & Antes do tratamento & Depois do tratamento \\
\hline & $a / 260^{\circ} \mathrm{C}$ & $a / 260^{\circ} \mathrm{C}$ \\
\hline 1 & $26,4 \mu \mathrm{m}(7,2$ ASTM $)$ & $160 \mu \mathrm{m}(2,0$ ASTM $)$ \\
\hline 6 & $13,5 \mu \mathrm{m}(9,1$ ASTM $)$ & $21,3 \mu \mathrm{m}(7,8$ ASTM $)$ \\
\hline 9 & $35,9 \mu \mathrm{m}(6,3$ ASTM $)$ & $15,4 \mu \mathrm{m}(8,8$ ASTM $)$ \\
\hline
\end{tabular}


A conclusão relevante obtida na Tabela 3 é que o controle do crescimento de grão nas temperaturas de processamento a quente do aço, a partir do uso de elementos microligantes adequados, pode refletir no tamanho de grão austenítico após o tratamento térmico final do material. Adiçôes de $\mathrm{Nb}$ e, principalmente, de Ti mostram-se interessantes neste sentido. Em especial, o Ti é interessante pela maior estabilidade dos nitretos e carbonitretos formados e à não formação de carbonetos eutéticos, como o ocorrido para o $\mathrm{Nb}$.(8) Em lingotes de grandes dimensões, a microssegregação do $\mathrm{Nb}$ facilita a formação dos eutéticos de carbonetos, mesmo que teores baixos sejam utilizados. Tais carbonetos diminuem sensivelmente a tenacidade do material, $\left({ }^{(}\right)$propriedade essencial para $\circ$ aço VMO, principalmente quando aplicado em matrizes de forjamento em martelo.

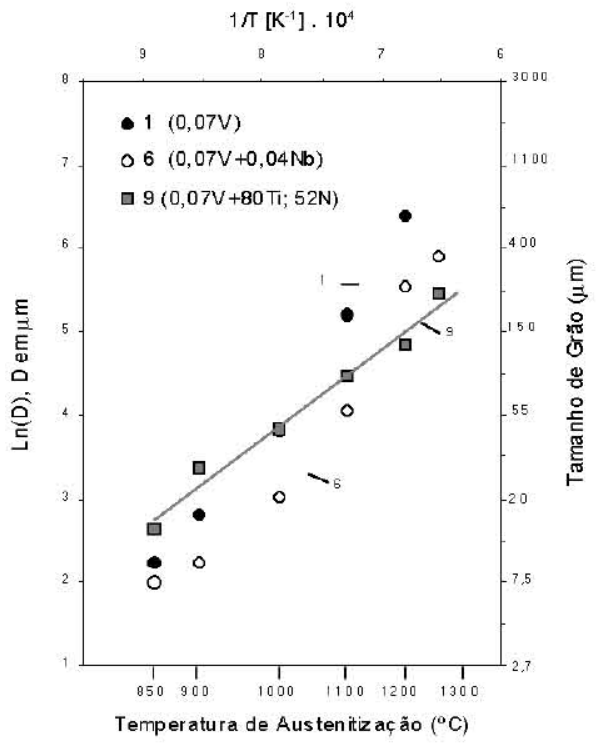

a)

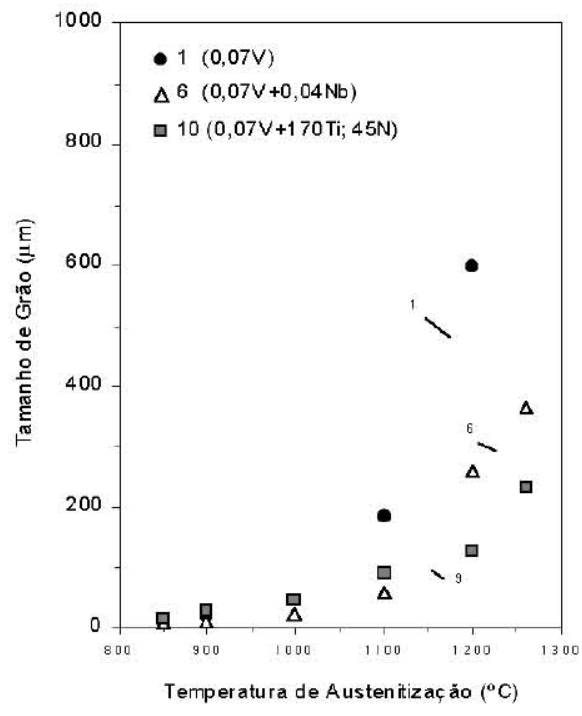

b)

Figura 4. Comparação do tamanho de gräo austenítico das ligas com $\mathrm{V}, \mathrm{V}+\mathrm{Nb}$ e $\mathrm{V}+\mathrm{Ti}$, em função da temperatura de austenitização. Tempo fixo de I hora para todas as temperaturas. Os teores de $\mathrm{V}$ e Nb indicados estäo em porcentagem em massa e os teores de Ti e $\mathrm{N}$ estäo em ppm. a) em escala logaritmica; b) em escala linear.

\section{CONCLUSÓES}

- As ligas contendo $\mathrm{V}, \mathrm{Nb}$ e $\mathrm{V}+\mathrm{Nb}$ apresentam dois estágios de crescimento de grão austenítico. As temperaturas de mudança de comportamento, $T_{c}$, são de aproximadamente $1000^{\circ} \mathrm{C}$ para as ligas com apenas $V \mathrm{e}$ $1050^{\circ} \mathrm{C}$ para as ligas com $\mathrm{Nb}$ e $\mathrm{V}+\mathrm{Nb}$.

- As ligas com V+Ti apresentam único comportamento do crescimento de grão austenítico, nas temperaturas entre $850 \mathrm{e} 1260^{\circ} \mathrm{C}$. Este deve estar associado à alta estabilidade dos nitretos e carbonitretos de Ti.

- Em temperaturas abaixo de $1000^{\circ} \mathrm{C}$, as ligas com $\mathrm{V}+\mathrm{Ti}$ possuem tamanho de grão austenítico maior que as ligas com $V$ ou com $\mathrm{Nb}$. Porém, o crescimento de grão ocorre em menores taxas de crescimento, tornando o grão austenítico sensivelmente mais refinado acima de $1200^{\circ} \mathrm{C}$.

- Para ser efetivo no controle do crescimento de grão em alta temperatura, o Ti deve ser adicionado em teores entre 80 e 170 ppm, considerando-se ligas com $N$ entre 40 e 55 ppm.

- O vanádio, mesmo em pequenas proporções, promove forte efeito no endurecimento secundário do aço VMO. Adições de outros elementos podem ser empregadas sem variaçôes nas reações de revenido, desde que o teor de $\bigvee$ não seja modificado.

- Os testes de aquecimento em alta temperatura indicam que o tamanho de grão prévio à conformação a quente, após o encharque, pode influenciar o tamanho de grão austenítico final obtido, no tratamento de têmpera final do material. Desta forma, o refino de grão em alta temperatura, com adição de Ti por exemplo, pode ser interessante para o aço VMO. 


\section{Agradecimentos}

Os autores agradecem ao Eng. Luis H. Guedes e ao Eng. Fábio A. Lazarini que realizaram parte do trabalho experimental, durante o estágio curricular do curso de Engenharia de Materiais da Universidade Federal de São Carlos.

\section{REFERÊNCIAS BIBLIOGRÁFICAS}

I. MILLER, O.O. Influence of austenitizing time and temperature on austenite grain size of steel. Transactions of ASM, v. 43, p. 260-270, Apr. 1951.

2. GLADMAN, T.; PICKERING, F.B. Grain-refined C-Mn Steels. Journal of Iron and Steel Institute, v. 205, p. 653662, Jun. 1967.

3. KESTENBACH, H.-J. Precipitação de carbonitretos em aços microligados. In: SIMPÓSIO AÇOS: PERSPECTIVAS PARA OS PRÓXIMOS 10 ANOS, 2002, Rio de Janeiro. Anais... Rio de Janeiro: Ivani Rott, 2002. p.95-I08.

4. MANOHAR, P.A.; FERRY, M.; CHANDRA, T. Five decades of the Zener equation. ISIJ INTERNATIONAL, v.38, n.9, p. 913-924, Sept. 1998.

5. CAHN, R.W. Recovery and recrystalization. In: CAHN, R.W.; HAASEN, P. Physical Metallurgy. 2. ed.. North Holland: Amsterdan, 1970. p.II29-I 197.

6. COLADAS, R.; MASOUNAVE, J.; GUÉRIN, G.; BAÏLON, J.P. Austenite grain growth in médium-carbon steels microalloyed with niobium. Metal Science, v. II, p. 509-5 I6, Nov. 1977.

7. NORDBERG, H.; ARONSSON, B. Solubility of Niobium carbide in austenite. Journal of Iron and Steel Institute, v. 206, p. 1263-1266, Dec. 1968.

8. MORI, F.Y; BARBOSA, C.A.; SOUZA, M.H.C.; FALLEIROS, I.G. Controle do tamano de grão austenítico de um aço para trabalho a quente através da adição de nióbio. In: CONGRESSO ANUAL DA ABM, 32., Anais... São Paulo: ABM, 1977. contribuição técnica n 1.389 ,

9. MESQUITA, R. A.; BARBOSA, C. A. Aços ferramenta de alto desempenho para matrizes de fundição sob pressão. Metalurgia e Materiais, v.59, n.539, p. 17-22, nov. 2003.

I0. KUNZE, J.; BEYER, B. ; OSWALD, S. ; GRUNER, W. Thermodynamic data of the formation of nitride in iron. Steel Research, v. 66, n. 4, p. 16I-166, Apr. 1995.

I I. PICKERING, F. B. Physical metallurgy and design of steels. London: Science Publishers, 1978. p. 63.

12. KUNZE, J. Solubility product of titanium nitride in g-iron. Metal Science, v. I6, p. 217-2 18, Apr. 1982.

13. NARITA, K. Physical chemistry of the groups IV A (Ti,Zr), V A ( , Nb, Ta) and rare earth elements in steel. Transactions of the Iron and Steel Institute of Japan, v. 15, p. 145-152, Mar. 1975.

14. MATSUDA, S. ; OKUMURA, N. Effect of distribution of TiN precipitate particles on the austenire grain size of low carbon low alloy steels.. Transactions of the Iron and Steel Institute of Japan, v. 18, p. 198-205, Feb. 1978.

I5. GOLDSCHMIDT, H. J. Interstitial alloys. London: Butterworths, 1967. p. 88-253

16. ADRIAN, H.; PICKERING, F. B. Effect of titanium addition on austenite grain growth kinetics of medium carbon VBv steels containing 0,008-0,018\% N. Materials Science and Technology, v. 7, p. I76- 182, Feb I99I.

17. PICKERING, F. B. Titanium nitride technology. In: KORCHNSKY, M.; GORCZVCA, S.; BLICHARSKI, M. PROCEEDINGS OF CONFERENCE ON MICROALLOYED VANADIUM STEELS. 1990.

18. WAGNER, C. Z. Zeit für Elektrochem, v. 65, p. 58I-59I, Jun. 1966 apud PICKERING, F. B. Titanium nitride technology. In: KORCHNSKY, M.; GORCZVCA, S.; BLICHARSKI, M. PROCEEDINGS OF CONFERENCE ON MICROALLOYED VANADIUM STEELS. 1990.

19. MEDINA, S. F; CHAPA, M.; VALLES, P. ; QUISPE, A.; VEIGA, M. I. Influence of Ti and N contents on austenite grain control and precipitate size in structural steels. ISIJ International, v. 39, n. 9, p. 930=936, Sept. 1999.

20. MANOHAR, P. A.; DUNNE, D. P.; CHANDRA, T.; KILLMORE, C. R. Grain growth predictions in microalloyed steels. ISIJ International, v. 36, n. 2, p. 194-200, Feb. 1996.

21. HILLIARD, J. E. Applications of quantitative metallography in recrystalization studies. In: MARGOLIN, H. Recristalization, grain grownth and textures. Metals Park, OH: ASM, 1966. p. 267-295. 